\title{
Tuff bands and the stability of coal mine slopes
}

\author{
K Koosmen PSM, Australia
}

\begin{abstract}
Tuff bands are a common geological feature in coal deposits throughout Australia and elsewhere throughout the world. They are typically comprised of fine-grained volcanic ash fall sediments, deposited parallel to bedding, in layers from several millimetres to more than several metres in thickness, and most commonly observed in low energy depositional environments which favour their preservation after they are first deposited. Individual tuff layers may be laterally continuous for several hundred kilometres and are almost always continuous across a deposit scale. This makes them particularly useful stratigraphic markers.

Whilst tuff bands are generally fine-grained, their geotechnical characteristics may vary widely from durable high strength rock, to clay that can be easily remoulded by hand. Where they exist in a soil-like or sheared condition, the presence of tuff bands within the stratigraphic sequence may increase the likelihood for slope instability. Complicating the matter is that shear strength characterisation can be hampered by the inability to collect and preserve samples which are adequate for laboratory shear strength testing.

The purpose of this paper is to discuss the geotechnical characteristics, shear strength characterisation and other significant factors for tuff bands in the context of coal mine slope stability. Following this, a number of failure mechanisms are identified for coal mine highwalls, dumped low walls, footwalls and dragline benches, citing several case studies from coal deposits where tuff bands have caused slope instability.
\end{abstract}

Keywords: coal mine slope stability, tuff bands, failure mechanisms

\section{Introduction}

\subsection{The occurrence of tuff bands in coal deposits}

Coal deposits are typically comprised of two main rock mass domains: 1) the actual coal seams which are of economic value for steelmaking and power production, and 2) the interburden and overburden waste rock which separate and overlie the coal seams. These non-coal waste units mostly comprise interbedded clastic sediments; predominantly sandstones and siltstones with lesser amounts of claystone and conglomerate. The relative proportion of different lithologies varies as a function of the depositional environment.

Pyroclastic sediments from volcanic ash falls, referred to herein as tuff bands, are also common geological features in many coal deposits around the world but typically only represent a very minor proportion of the overall stratigraphy. In the New South Wales (NSW) Hunter Valley and Queensland (QId) coal mining basins the tuff units mostly occur as discrete intraseam bands within larger coal seams, or between thinly bedded coal seams. In these areas the tuffaceous units generally comprise less than $5 \%$ of the overall sequence, and often much less. The Newcastle Coal Measures of NSW are a notable exception from the norm, where hundreds of tuff layers from $1 \mathrm{~mm}$ up to $25 \mathrm{~m}$ thick comprise around $\sim 20 \%$ of the overall sequence (Diessel 1985). This percentage is anomalously higher however, as several tuff units are more than $10 \mathrm{~m}$ thick.

\subsection{The use and implications for tuff bands in coal mining}

The presence of tuff bands within a coal deposit can have several potentially significant implications for the exploration and geological understanding of the deposit and broader-scale basin.

Because they are laterally continuous and tend to have unique geochemical and/or geophysical signatures, tuff bands can be used as stratigraphic markers to correlate the stratigraphy at a deposit or regional scale 
(Kramer et al. 2001; Bayly 2012). Volcanic ash is also rich in minerals such as sanidine, plagioclase and zircon which are suitable for radiometric dating techniques, Bohor \& Triplehorn (1993). This can assist with determining factors that are relevant to the genesis of deposits such as geological time scales, sedimentation rates, basin development and volcanic history (Gulson et al. 1990; Bohor \& Triplehorn 1993; Huff 2016; Dai et al. 2017).

The distribution and abundance of tuff bands within a coal deposit may also have several potentially significant implications for the mining strategy. In underground coal mines the tuff units can represent significant geotechnical hazards for roof, floor and pillar stability (Seedsman \& Mallet 1988; Sainsbury 2003; Galvin 2016). This is largely the result of the propensity for tuff to swell, degrade, and reduce in strength when unconfined and when exposed to water or humid conditions. Degradation of tuff units within the immediate roof may require additional support or that a coal rib be left in place. Floor heave and roof collapse can also occur when vertical stresses in coal pillars exceed the bearing capacity of softened tuff units in the roof or floor. In adverse cases this can cause the floor to heave up and come into contact with the roof, or in less adverse cases, cause gradual uplift and impact serviceability of infrastructure such as conveyor belts.

In open cut coal mines, the distribution of tuff bands within coal seams can reduce coal quality. Separation of tuff units from the coal requires selective mining methods at the time of extraction or more rigorous coal processing techniques; both of which can add significant costs to overall coal production. In more extreme cases tuff bands may have such a significant impact on coal quality that the deposit is ultimately uneconomical (Hutton 2009; Beckett 1988).

Tuff bands of poor geotechnical character may also have major implications for slope stability during open pit mining. As a result of their geological origins, the tuff bands within rock slopes, footwall slopes or spoil pile foundations may be clay-rich, low strength and extremely persistent. If the slopes are not adequately designed with these factors in mind, very large slope failures can develop, with known failure cases of more than 30 million cubic metres.

\subsection{Scope of this paper}

This paper seeks to explore several factors regarding the formation and engineering geological aspects of air fall tuff deposits which are of significance for slope stability in open pit coal mines. Following this, several examples are given where tuff bands have resulted in highwall, low wall and footwall instability of varying scales. Whilst the paper mostly draws on experience from Australian coal deposits, the learnings may be applicable to many other coal deposits elsewhere throughout the world with similar conditions.

\section{Geological origins of tuff}

Explosive volcanic eruptions eject mixtures of gas and rock fragments known as tephra into the atmosphere. The fragments are classified according to their particle sizes as volcanic boulders or blocks (>64 mm), lapilli (2-64 mm) or volcanic ash ( $<2 \mathrm{~mm})$. According to the model from Diessel (1985), tephra is deposited from an eruption by three primary mechanisms, Figure 1 :

- Pyroclastic flows: Comprising a hot fluidised mixture with a high particle to gas ratio, forming for example from the collapse of the explosion column and with flow resembling something like a hot mudflow. High residual heat may result in a high degree of welding.

- Pyroclastic surge: Comprising lower particle to gas ratio than a pyroclastic flow and with clasts carried laterally by a near-ground and rapidly moving turbulent gas cloud due to something like a directed blast.

- Pyroclastic (ash) fall: the falling of ash particles from the atmosphere, and more analogous to 'dust settling' than the relatively dynamic depositions associated with flows or surges. Ash may come from the main tephra column following the primary eruption or from secondary ash clouds which form above flows or surges. The time in suspension also provides opportunity for cooling which reduces the amount of heat welding in ash falls compared to surges and flows. 


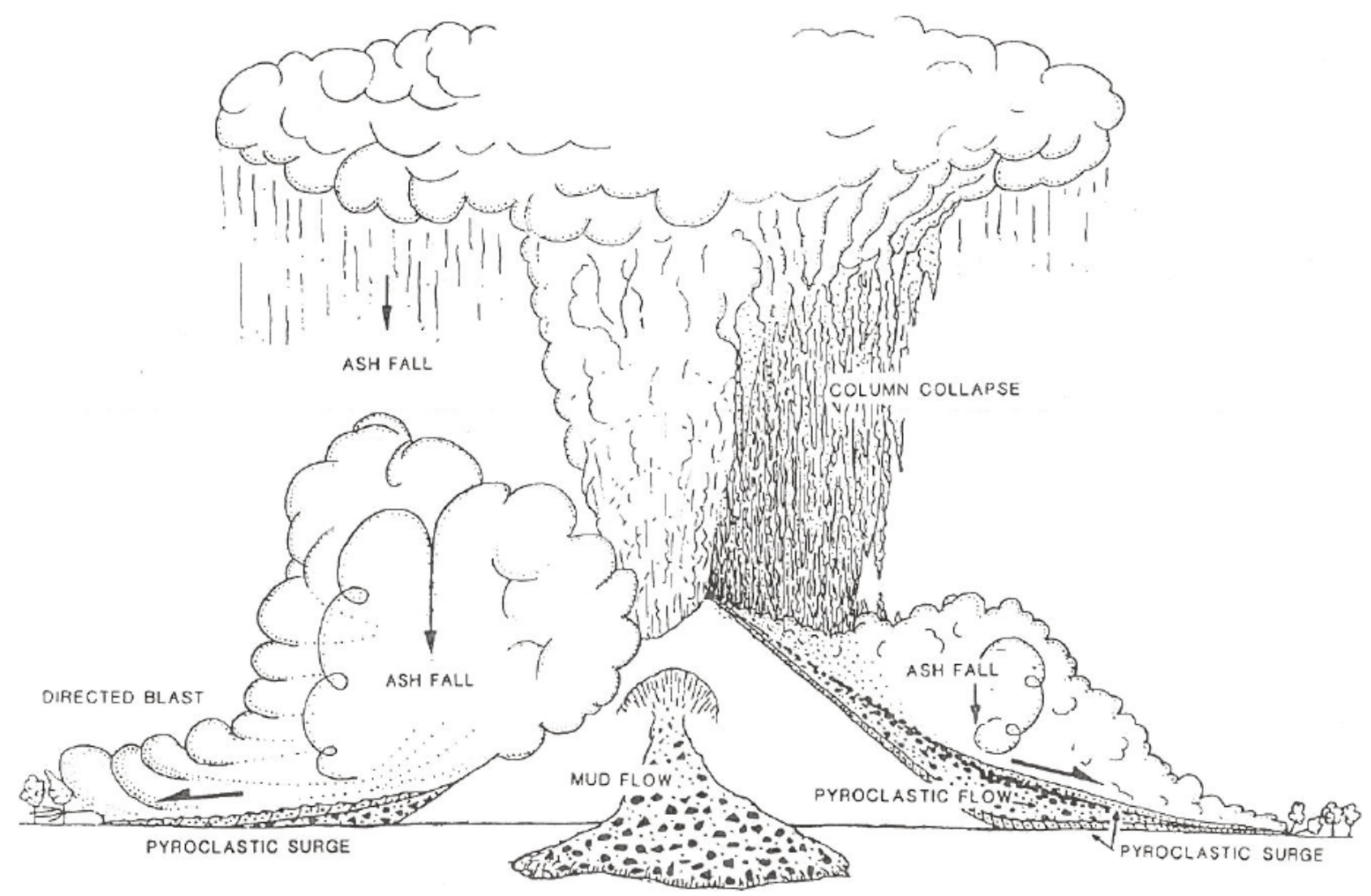

Figure 1 Mechanisms for the deposition of tephra following a volcanic eruption (after Diessel 1985)

Following an eruption the volcanic ash may extend hundreds or even thousands of kilometres from the source depending on the scale of the eruption and prevailing climatic conditions at that time. This produces tuff bands which are laterally extremely persistent but with a unit thickness that is many orders of magnitude less. Because larger particles fall out of suspension more readily, tuff bands may exhibit a fining up sequence, or exhibit numerous layers resulting from several closely timed eruptions.

The volcanic ash can be deposited anywhere throughout the coal-bearing sequence depending on the depositional phase that is ongoing at the time of eruption. Deposition may be subaqueous (into coal swamps, submerged delta plains or marine settings) or subaerial onto parts of the basin which are not submerged underwater. The depositional environments best suited to the preservation of volcanic ash and conversion into tuff bands are coal forming environments in shallow lakes, ponds, and swamps where depositional energy is low, where plants act to restrict the inflow of clastic sediments and where ongoing peat accumulation leads to rapid burial and preservation of tuffs (Diessel 1992). In contrast, deposition into deeper marine environments may be less preservative due to tidal or turbidity currents from wind and wave action, whilst subaerial deposition may be later subject to erosive action from wind and rainfall.

For these reasons the majority of tuff bands in coal deposits are observed as relatively thin bands contained with coal seams, whilst tuff bands occurring in interburden units are less common but often have greater thicknesses (as a general rule). An extreme example of the latter is the 25-m-thick Awaba Tuff in the Newcastle Coal Measures of NSW, which forms the roof for the Great Northern Seam. In this instance, the ash deposit appears to have been of sufficient thickness to bury the coal swamp, kill the plant life and terminate coal formation. Although tuff bands from the Newcastle Coal Measures have been correlated with those further west in the Wollombi Coal Measures of the Hunter Coalfield (Kramer et al. 2001), and the Illawarra Coal Measures in the Southern Coalfields (Grevenitz 2003), neither contain tuff units of comparable thickness to the Awaba Tuff and probably indicates that the Newcastle Coalfields were closer to the volcanic source (possibly as closely as $40 \mathrm{~km}$ offshore; Diessel 1992). 


\section{Mineral composition}

Most air fall tuff deposits are derived from felsic rhyolitic or dacitic magmas with high viscosity and high gas contents capable of generating explosive eruptions with high amounts of energy (Gulson et al. 1990; Diessel 1992; Bohor \& Triplehorn 1993; Kramer et al. 2001; Huff 2016). Air fall tuff deposits derived from mafic magmas have been cited in some coal basins around the world (Bohor \& Triplehorn 1993; Dai et al. 2017), but are relatively less common. As a result of their typical felsic origins, the primary minerals in ash fall deposits are predominantly quartz, feldspars and biotite with lesser amounts of other volcanic minerals such as apatite, Ilmenite, magnetite and zircon (Bohor \& Triplehorn 1993; Kramer et al. 2001; Dai et al. 2017).

Whilst clay minerals are synonymous with tuff bands in coal deposits, the clay constituents are not primary minerals of ash fall deposits. Rather, they form as secondary authigenic minerals from post-depositional alteration processes, with the type and abundance of different clay minerals very much dependent on primary mineral composition and the depositional environment. Although there are some minor inconsistencies in their definitions (Zhao 2012; Dai et al. 2017), the literature generally classifies altered tuff bands as tonsteins or bentonites.

The term tonstein is usually reserved for tuff bands which form as kaolinite-rich layers in non-marine coal-bearing environments that are acidic, organic-rich and which provide favourable leaching conditions. This assists with the kaolinisation of volcanic glass and other minerals, such as feldspars, amphiboles and pyroxenes (Bohor \& Triplehorn 1993). The term bentonite is usually reserved for tuff bands which form as smectite-rich layers deposited into marine settings. Alteration processes may include deuteric alteration, hydrothermal alteration and subaqueous devitrification. Diagenesis of bentonites also frequently alters smectite to illite, resulting in mixed-layer K-bentonites. Whilst most bentonites and K-bentonites are smectite or illite/smectite-rich, some may also contain a considerable amount of kaolinite (Huff 2016).

Although this broad tonstein-bentonite classification system is generally accepted in the literature it can be somewhat misleading as the principal clay minerals which form in each setting are also common in tuff bands that were formed in the other. For example, ash deposited in marine environments can alter to kaolinite occasionally so that bentonites are not necessarily always smectitic, Schultz (1962). Furthermore, Gulson et al. (1990) reports that smectite and mixed-layer clay minerals are common constituents of Australian coals and usually concentrated mainly in tuff derived clay bands. Tonstein beds which are thicker than about $150 \mathrm{~mm}$ and deposited in a coal forming environment may also be kaolinised at their peripheries, but comprised of a smectite core due to the limited access for freshwater for alteration (Bohor \& Triplehorn 1993). Very thick inter-seam tuff bands may also tend to retain more of their original pyroclastic character and show greater preservation of the primary minerals.

Whilst there is a great deal of literature regarding the mineralogy and alteration of ash fall tuffs, a more detailed review is beyond the scope of this paper. Notwithstanding this, the review has indicated that tuff bands in coal seams tend to be more kaolinite rich, whilst tuff bands deposited in marine settings may be more smecitite rich. However, these minerals are not mutually exclusive to the respective depositional environments, as bentonites and tonsteins can both contain a significant proportion of kaolinite, illite or smectite. For the remainder of this paper, the term 'tuff' will be retained to collectively describe all air fall tuff deposits in coal basins, regardless of their deposition environment and inherent mineralogy.

\section{$4 \quad$ Physical processes and tuff band characteristics}

Whilst mineralogy is an important factor that can influence the geotechnical character of a tuff band, several other processes can also have a significant impact on the geotechnical character. These processes can be broadly classified as geological or mining induced, with several key aspects discussed in further sections.

\subsection{Cementation}

Pyroclastic flows and pyroclastic surges are often heat welded upon deposition due to the fusing of particle contacts from residual heat. Volcanic ash has a much longer residence time in the atmosphere which causes 
cooling, and for this reason, the volcanic ash is generally not heat welded on deposition. Hardening and induration of ash fall tuffs then occurs during diagenesis due to the combined effects of consolidation, low-grade metamorphism, cementation and the recrystallisation and replacement of primary minerals.

Very high levels of induration may be observed in some air fall tuffs. The author is aware of one mine site in the Hunter Valley of NSW where a tuff unit, the Fairford Claystone, is crushed and used as sheeting material for roads and stemming gravel. It has excellent durability properties and high unconfined compressive strength (UCS) typically in the range of 60 to $80 \mathrm{MPa}$, Figure 2. Elsewhere in the Newcastle Coal Measures of NSW some tuff units are described as cherts, with Sainsbury (2003) reporting UCS values as high as 140 MPa.

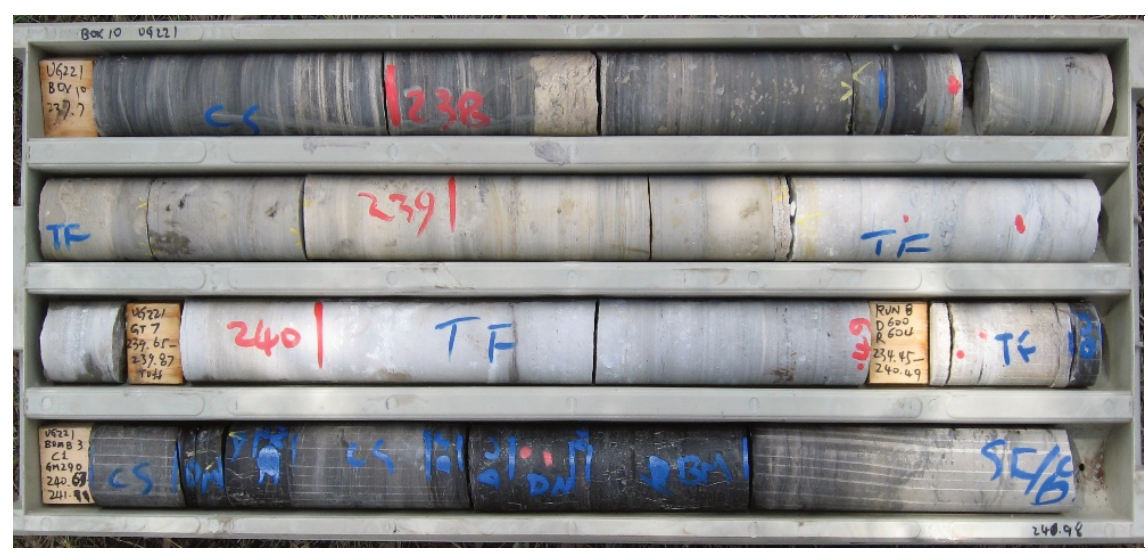

(a)

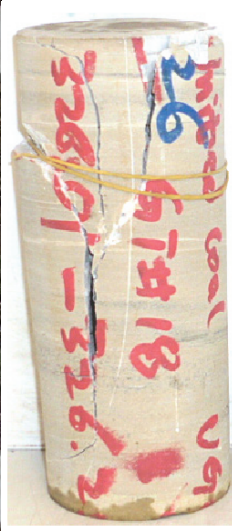

(b)

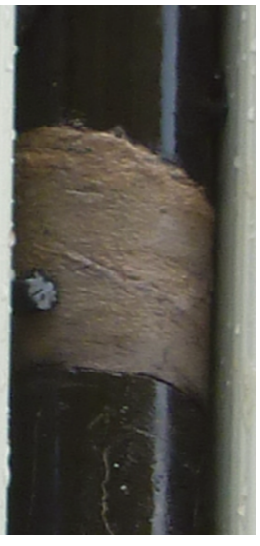

(c)

Figure 2 (a) Tuffaceous Fairford Claystone in middle two core runs; (b) Fairford Claystone after unconfined compressive strength testing, giving UCS value of $69 \mathrm{MPa}$; and (c) Soil-like tuff unit in freshly drilled core, showing low apparent degree of cementation

At the other end of the scale tuff units may be transitional materials somewhere in the hard soil to very weak rock range. Although these tuff bands have been subject to diagenetic processes, the apparent soil-like character can be attributed to a lack of cementation. According to Seedsman \& Mallet (1988), poorly cemented tuffs may have been deposited into well drained environments with extensive leaching of cementitious minerals. Clay mineralogy may also limit cementation if it can inhibit processes such as recrystallisation. The behaviour of these weakly-cemented and soil-like tuff units may be more comparable to an over-consolidated clay rather than a rock. An example is shown on the right of Figure 2, where the tuff band could be easily peeled with a pocket knife. Induration may also be partly reversible due to swelling with further discussion on this topic provided below.

\subsection{Tectonic deformation}

Where tuff bands have a low degree of cementation their 'intact' shear strengths may be considerably lower than coal seams and other sedimentary rocks within the sequence. Under a sufficient in situ stress regime this may cause the concentration of strains along weak tuff layers and manifest as laterally extensive beddingparallel shears. In these instances, the shear strength will obviously be reduced from an intact to a residual condition.

As tuff bands often have much lower strengths than the overlying units, they are also prone to drilling-induced damage which can lead to false identification of sheared in situ conditions. It is often difficult to differentiate drilling damage from bedding shears based only on core photographs as illustrated in Figure 3. High clay contents can add a further complication if drilling incises grooves into the core, or if core is allowed to dry out and desiccate. These features can (falsely) give the appearance of a sheared tuff band in core photographs. Thus, caution may be required if the core photographs are heavily relied upon during compilation of the geotechnical model. 


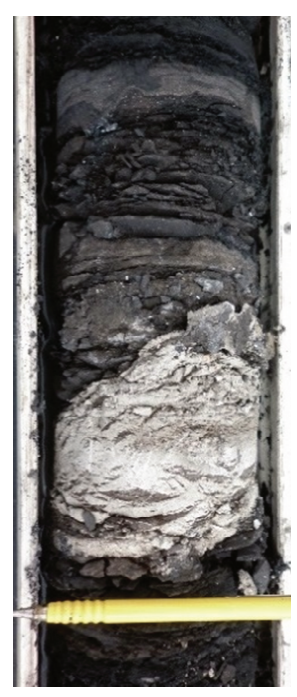

(a)

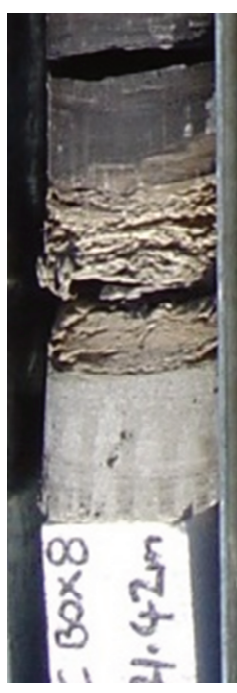

(b)

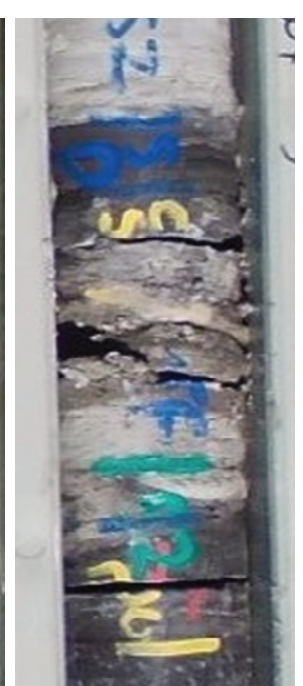

(c)

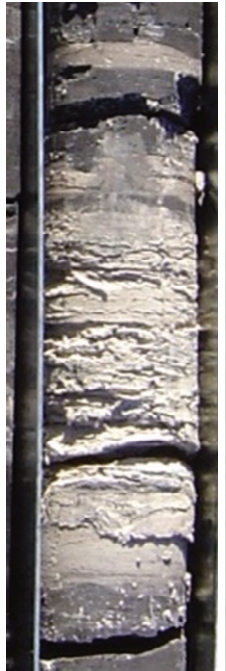

(d)

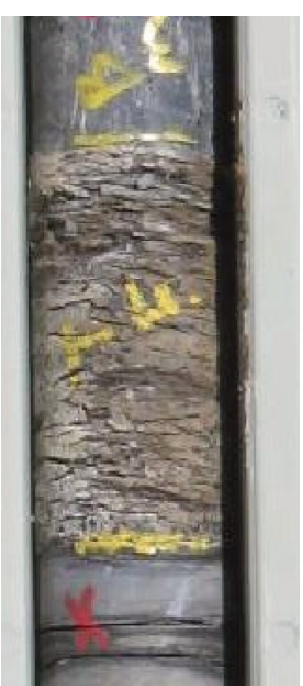

(e)

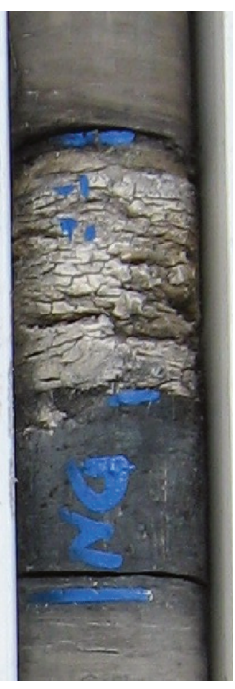

(f)

Figure 3 Examples of tuff bands from core drilling: (a) and (b) Sheared tuff bands; (c) Tuff band broken from drilling; (d), (e) \& (f) Tuff bands that appear sheared in core photographs but are gouged by the drill bit cutting into the soft core (d) or desiccated due to drying out (e) and (f)

\subsection{Swelling behaviour}

Swelling of clays and weak rocks refers to the propensity for volume change in response to a reduction in confinement and the uptake of water. According to Taylor \& Smith (1986) there are two main mechanisms by which this occurs:

- Mechanical swelling: where volume change occurs as an elastic response due to a reduction in confining stress. Expansion induces a negative porewater pressure which draws water into the pores between the grains within the rock. This largely depends on the unloading modulus.

- Physio-chemical swelling: where volume changes occur via the absorption of water into the chemical structure of clay minerals. Smectites have the highest swell potential (particularly where sodium rich), followed by illite then kaolinite. Swelling and water uptake will only occur if the swelling pressure associated with the volume change exceeds the applied effective stress (i.e. if in situ stresses can no longer counteract the swelling pressure). Likewise, swelling clays may also be prone to shrinkage upon drying, which can lead to desiccation (Figures 3(e) and 3(f)).

Diagenesis and uplift of coal basins occurs over geological timescales which provides ample time for water content changes to equilibrate during the swelling processes detailed above. It is therefore reasonable to assume that tuff bands are not actively swelling (or consolidating) in virgin ground conditions (i.e. their moisture contents are in equilibrium).

Open pit excavation represents a large and relatively rapid reduction in the lithostatic pressures which reduces confinement and can induce swelling. Consider Figure 4, as an example, where Point $A$ is a considerable distance from the excavation with minimal change to the stress field. Closer to the excavation the slopes will de-stress as a result of overburden removal (B and $C)$. The confining stress may be particularly low where tuff bands remain at shallow depths in the floor, or effectively zero if the immediate seam floor is comprised of tuff (Point C). Assuming Point $\mathrm{C}$ has swelled to equilibrium, in-pit spoil placement may then increase the confining stress and introduce transient undrained conditions with positive excess pore pressures in the tuff bands (Point $D$ ). 


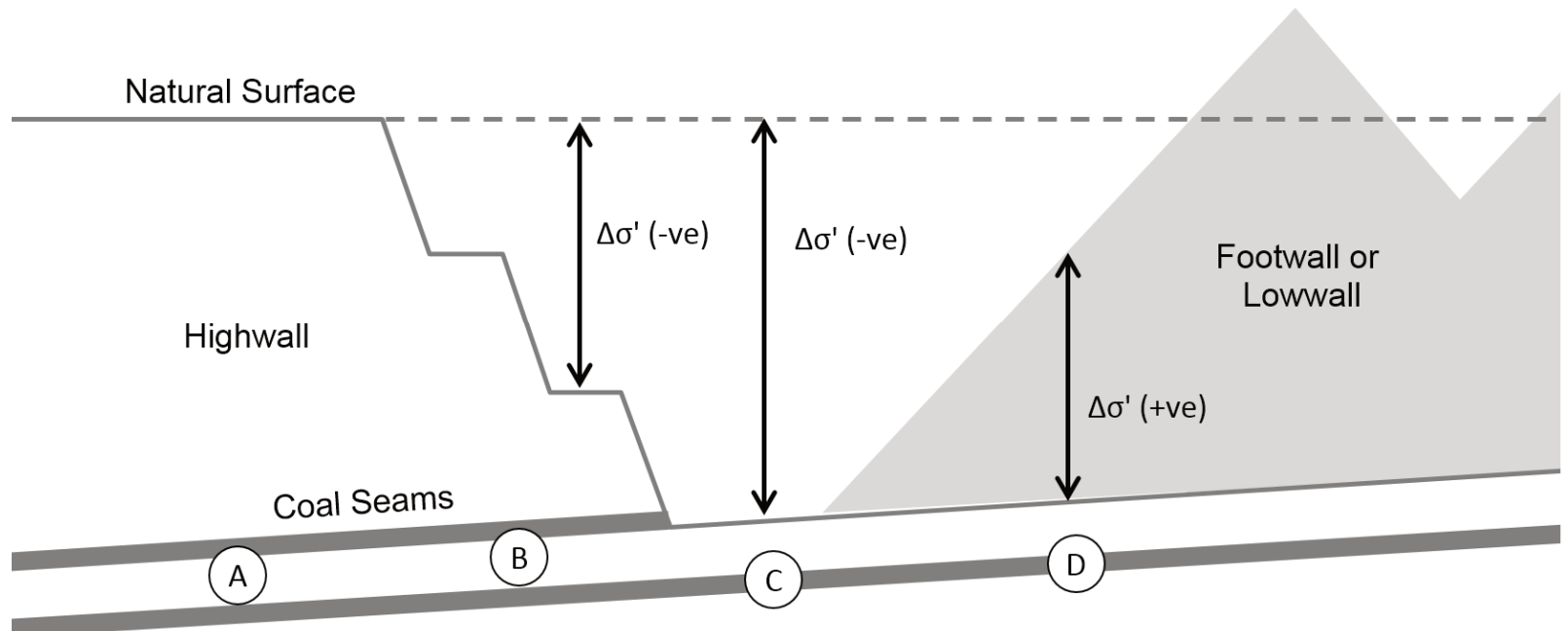

Figure 4 Illustration of changes to overburden pressure in different areas of a typical strip mine. Assuming coal seams contain tuff bands

Whilst this is all very much dependent on the inherent swelling characteristic of the tuff, it also requires the time-dependent ingress of water. Mechanisms for this may include infiltration of rainfall or in-pit water storage, upwards flow due to relief or artesian pressures and suction effects induced as a result of mechanical swelling. The reduction in confinement as a result of mining may also assist with water ingress by increasing the rock mass permeability.

Although swelling phenomena is not well document in tuff bands in open pit coal mining, the same fundamental principles have been investigated in great detail by Seedsman \& Mallet (1988) and Sainsbury (2003) for coal pillars in underground coal mines. In one of the more extreme cases from Seedsman \& Mallet (1988) a tuff specimen was loaded to $27 \mathrm{MPa}$ in unconfined compression before terminating the test prior to failure. The same specimen was then allowed to swell for several days in a triaxial cell under a mean confining pressure of $100 \mathrm{kPa}$ (in the context of open pit mining, this stress may be equivalent to around $5 \mathrm{~m}$ of cover), then was retested to failure at $1 \mathrm{MPa}$. In this instance the swelling increased the moisture content by $15 \%$. Martin \& Stacey (2018) use the term 'softening' to refer to this same phenomenon in swelling mudrocks which can lead to delayed failure of open pit slopes.

It is also important to note that whilst some tuffs may swell, others may exhibit very little tendency for swelling and degradation (for example, the Fairford Claystone in Figure 3).

\subsection{Mining-induced progressive failure}

Open pit excavation relieves horizontal and vertical stresses in the pit walls and pit floor. This causes the pit walls to displace inwards and the pit floor to displace upwards. Horizontal stresses redistribute around the base of the excavation which rotates the stress field near to the excavation boundaries and increases the shear stress along weaker layers such as sub-horizontal tuff bands, Figure 5. Whether or not slope failure occurs will depend on the shear strength that can be mobilised not only along the weaker layers, but also throughout the entire slope, collectively in all units, as a function of the incipient strains. In-pit dumping or nearby underground mining can also impact the stress field.

Due to variability in the stress-strain characteristics, the peak strength in some parts of a slope may be exceeded before the peak strength is mobilised in other parts. This concept - that different parts of a slope reach failure at different times - forms the basis of a concept known as 'progressive failure' (Bjerrum 1967; Duncan et al. 2005; Chowdhury et al. 2010; Martin \& Stacey 2018). Strain concentration in tuff bands can result in shearing if sufficient stresses accumulate to cause a shift from peak to residual strength. Whilst this may cause lipping along tuff bands in highwalls or floor heave in low walls, the overall slope can remain 'stable' if other parts of the slope can accommodate additional stress after the tuff bands lose strength and 
reach a residual strength. Otherwise if the other parts of the system cannot withstand the additional loading, then large-scale slope failure may result.
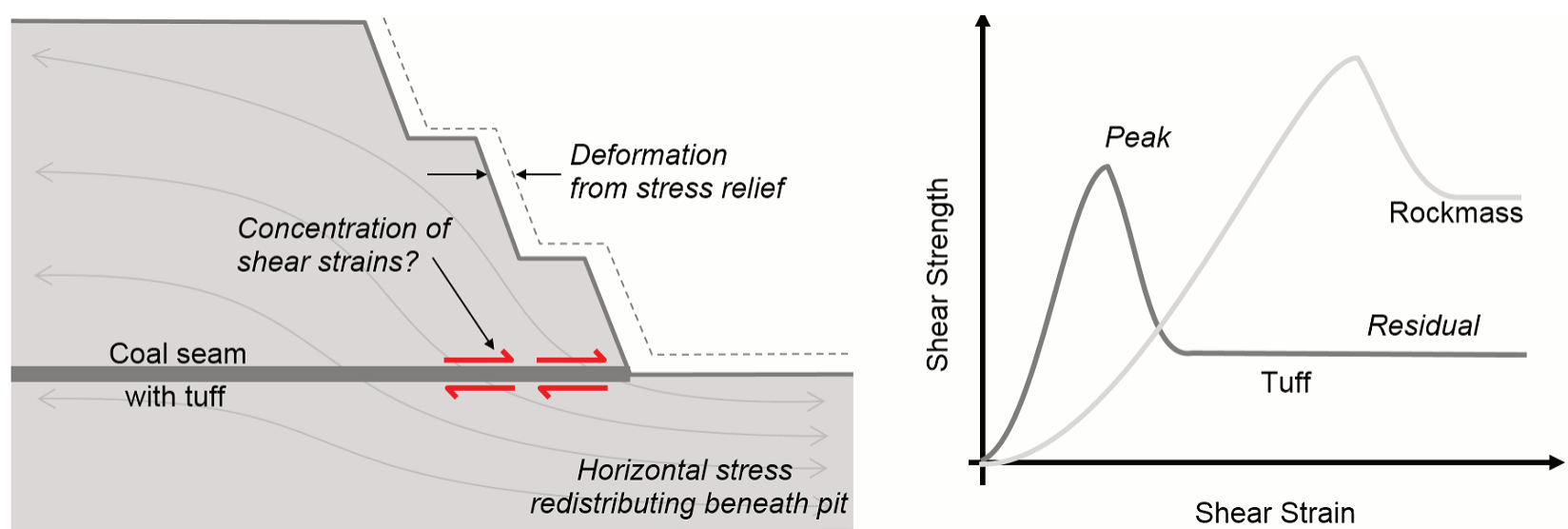

Figure 5 Illustration of how lipping may occur due to the modified stress field from open pit excavation

The influence of time may also be an important factor due to the effects of slope creep movements, where creep is defined as an increase in strain under a constant stress. For intact tuff bands loaded near to peak conditions, minor additional strains occurring as creep deformation may reduce the available shear strength to some post-peak value or the residual state. Although this may take many years to develop, it can result in delayed slope failures.

\section{$5 \quad$ Shear strength characterisations}

\subsection{Introduction}

The shear strength of tuff bands can be highly variable due to several factors discussed above. A number of these factors are referred to as 'cohesion-loss' mechanisms by Martin \& Stacey (2018), who proposed the shear strength model shown in Figure 6 for mudrocks which exhibit characteristics and water sensitivity like some tuff bands. The model is fundamentally the same as that which was proposed by Skempton (1970) for over-consolidated clays; except Skempton (1970) uses the term fully-softened state instead of cohesion-loss which he describes as the 'peak drained shear strength of clay under normally consolidated conditions'.

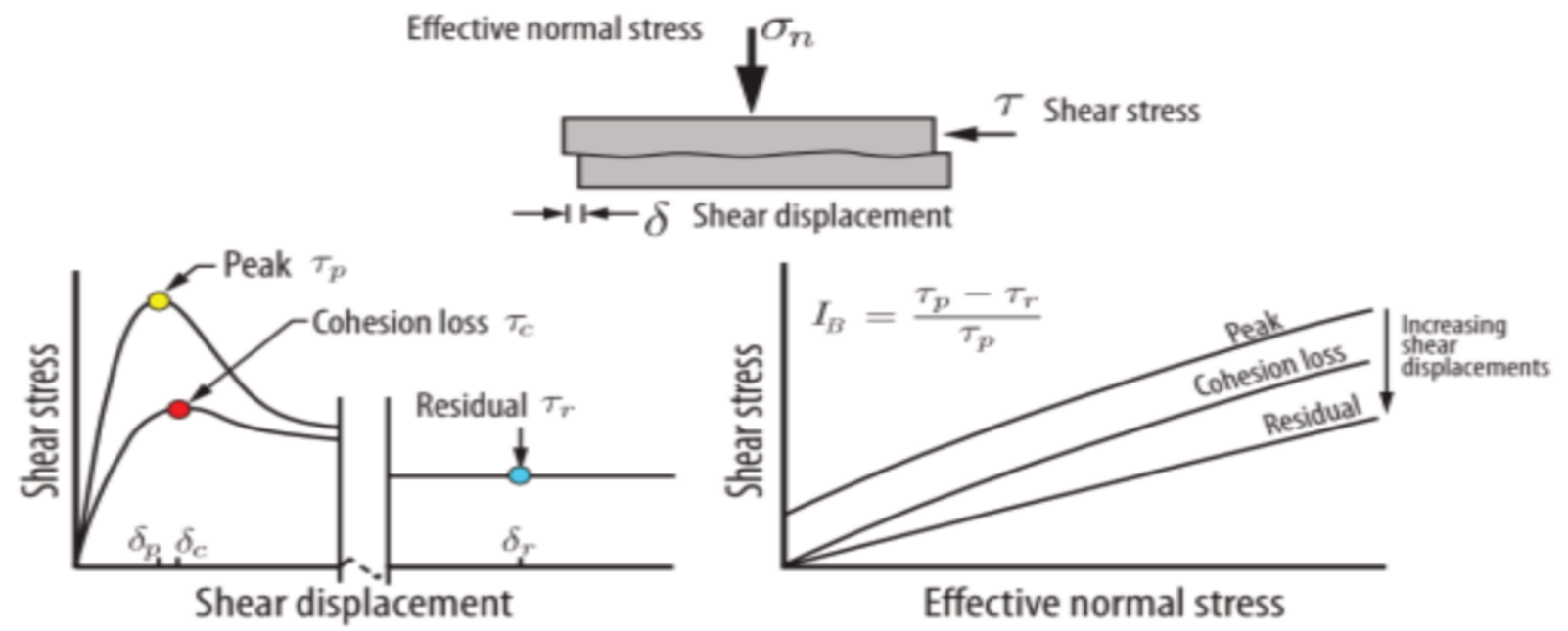

Figure 6 Cohesion-loss shear strength model. Image from Martin \& Stacey (2018)

With this conceptual model and different strength modes in mind, the following chapters discuss the merits and potential flaws with several approaches that are commonly adopted to derive tuff band shear strengths. 


\subsection{Laboratory strength testing}

Laboratory testing tends to focus on characterising the shear strength of poor quality tuff bands which are more critical for slope stability. There are several available methods which can be used to provide a direct measure of shear strength in the laboratory, such as triaxial, direct shear and ring shear tests. There are, however, some factors which complicate the laboratory testing of tuff bands, which include:

- Weak or sheared tuff may be prone to damage or core loss as a result of drilling, particularly if adjacent units are high strength and require aggressive drilling techniques.

- Tuff may be prone to slaking and swelling after it is drilled, as a result of water addition during drilling and the release of confining stress following extraction from the ground.

- Samples can be friable making them prone to breakage during handling, sample preparation and testing, particularly if testing at high stress.

- Laboratory specimens may not be representative of in situ conditions due to changes in the specimens after sampling and changes to the in situ state after drilling.

In light of these difficulties, the sections below provide a discussion of laboratory methods that are available for shear strength characterisation of tuff bands and the relative merits of each. The examples utilise data from projects which the author has been directly involved with, and legacy data which has been inherited from other projects.

\subsubsection{Triaxial testing}

Triaxial techniques are most commonly adopted for testing intact specimens; typically, Hoek triaxials for rocklike tuff materials or consolidated drained (CD) or consolidated undrained (CU) triaxials for soil-like materials.

For the conventional 'soil' triaxials there are several aspects that need to be considered. Firstly, conventional $\mathrm{CU}$ or CD triaxials typically employ a back saturation phase, where water is forced into the specimen under low confining pressures. This provides ideal conditions to promote swelling, if the mineralogy is susceptible, and may cause a strength reduction relative to the in situ non-swollen material (refer to example from Seedsman \& Mallet (1988) cited in Section 4.3). Secondly, multistage tests are commonly employed whereby a specimen is subject to several test stages over a range of confining pressures. Although this offers economies in terms of cost, time and sampling requirements, the earlier test stages can have strengthreducing effects on the later stages which must be considered during interpretation of the results.

This is highlighted by the example in Figure 7, where the first stage recorded a higher peak strength than the second stage, despite adopting a lower confining pressure. This indicates strength loss due to failure in the first stage, causing strength reductions in the second and third stages relative to what might be recorded using three virgin intact samples. Envelope A shows that a high cohesion and low friction angle are obtained if the 'peak' strength failure envelope is defined using the peak strengths recorded in each of the test stages. An alternate interpretation is offered by Envelopes B and C, cognisant of the fact that the first stage may be representative of peak strength, but the latter stages may be converging towards a fully softened or residual condition. In the case of Envelope B, definition of the peak strength is also made difficult by only having one data point, from which the slope and intercept values are indeterminate. 


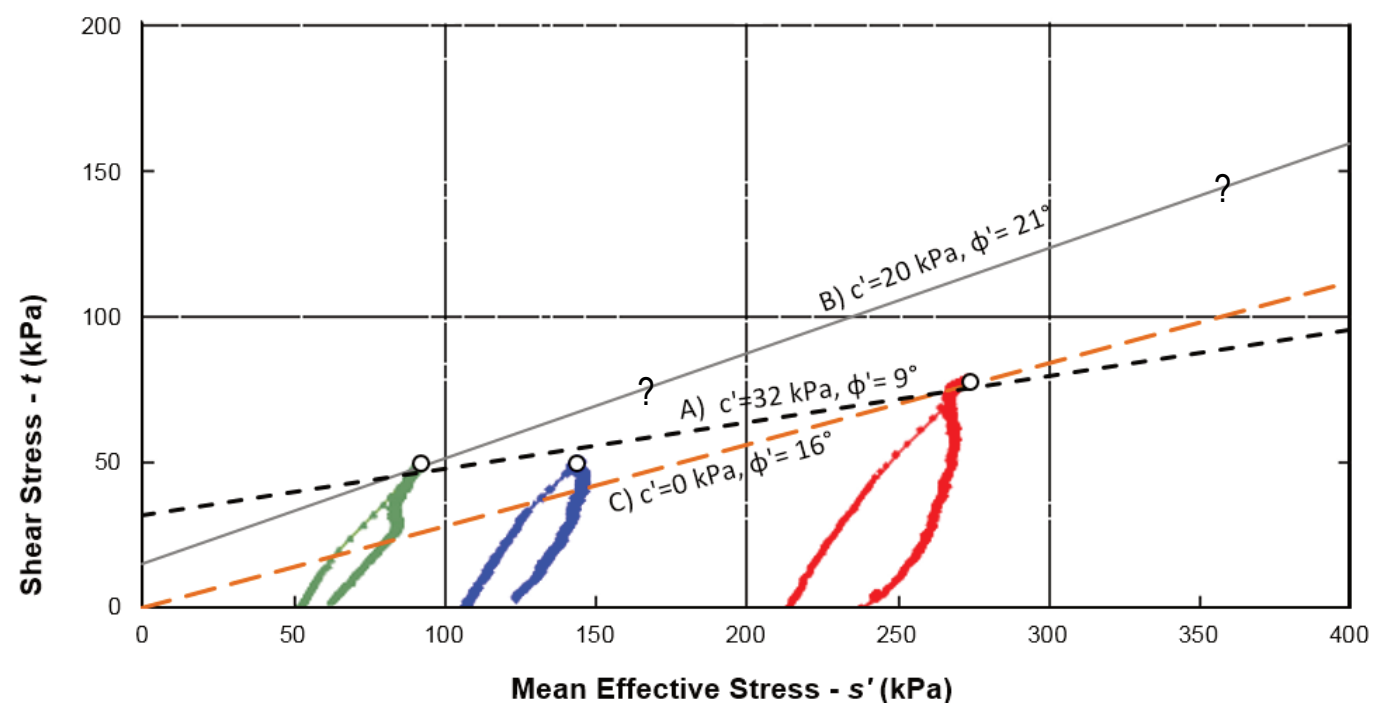

Figure 7 Results from multistage consolidated undrained triaxial testing of a clay tuff bands, showing multiple and widely varying interpretations of shear strength envelopes

\subsubsection{Direct shear testing}

Direct shear testing is the most commonly employed method for characterising the intact and defect strength of coal mine tuff bands. Because testing also commonly employs multistage techniques, the same issues are frequently observed as those discussed in the previous section for multistage triaxial testing. Due to brittle behaviours, characterisation of the peak intact strength requires that the several intact samples be tested over a range of stresses. This approach has been undertaken for direct shear testing of the tuff materials in Figure 8 which were all taken from the same deposit (but different seams). In this instance, the intact strength envelope is characterised by a higher friction angle and higher cohesion than the residual strength envelope, and is consistent with the model presented in Figure 6 . Notably though, the peak intact strength is not particularly high for these samples. Swelling may have contributed to some softening of these samples, as the original consultants specified that the samples be soaked in a water bath overnight before testing, as it was 'suspected that samples dried out during sampling'.

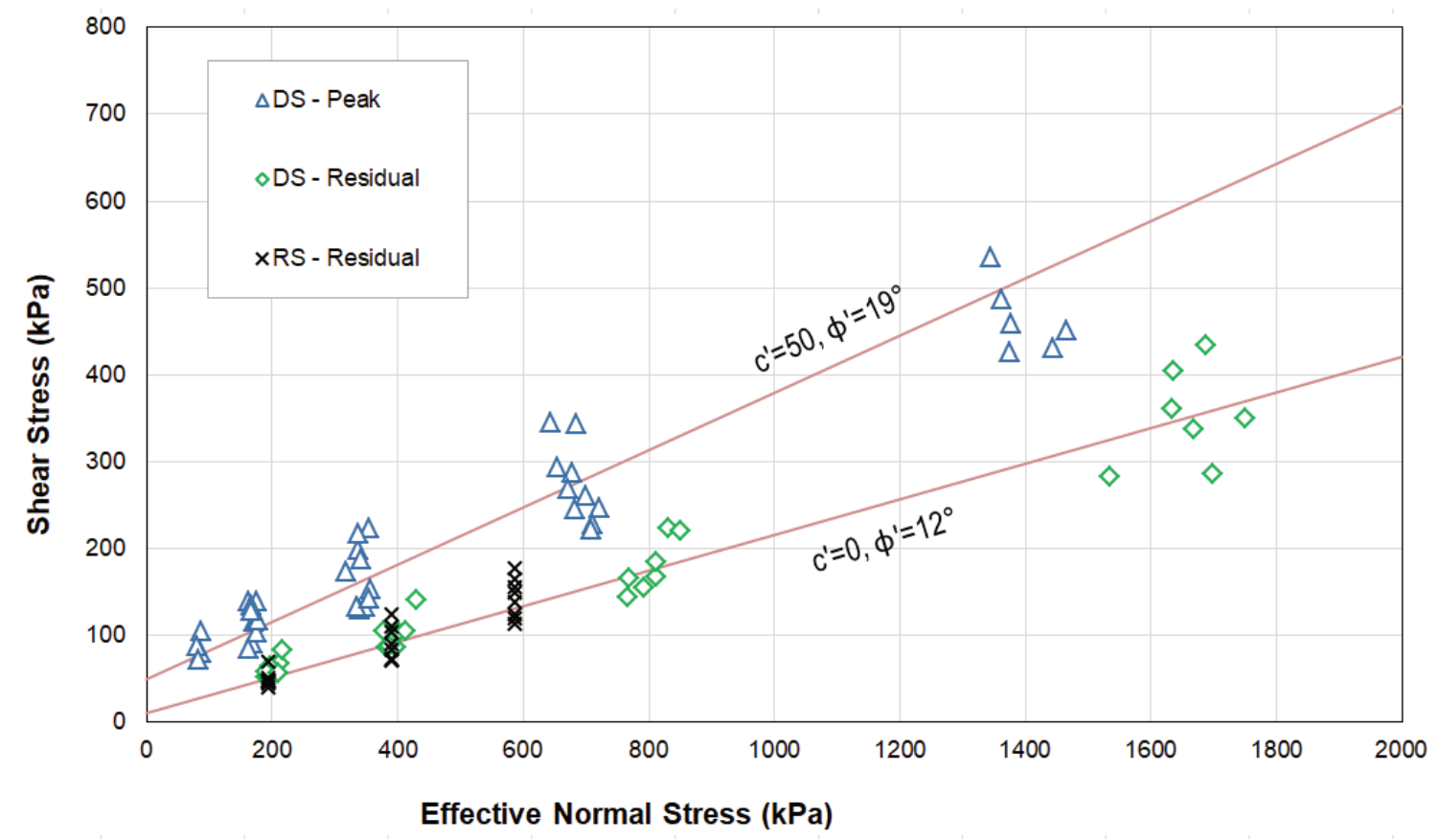

Figure 8 Results from single stage direct shear testing of intact tuff specimens that were soaked overnight prior to testing. DS refers to direct shear and RS refers to ring shear 
Figure 9 shows the residual shear strength of tuff band defects from several mine sites throughout NSW and Qld. Behaviour generally complies with the classic model for clean rock joints involving dilation at lower stresses as a function of roughness and crushing of asperities at higher stress. This crushing component can be greatly exacerbated in tuff defects however, as the asperities have a low strength and begin to crush under low stress conditions. Failure envelopes for defects with larger asperities may therefore exhibit pronounced curvature, like the envelope which demarcates the upper bound of the dataset in Figure 9.

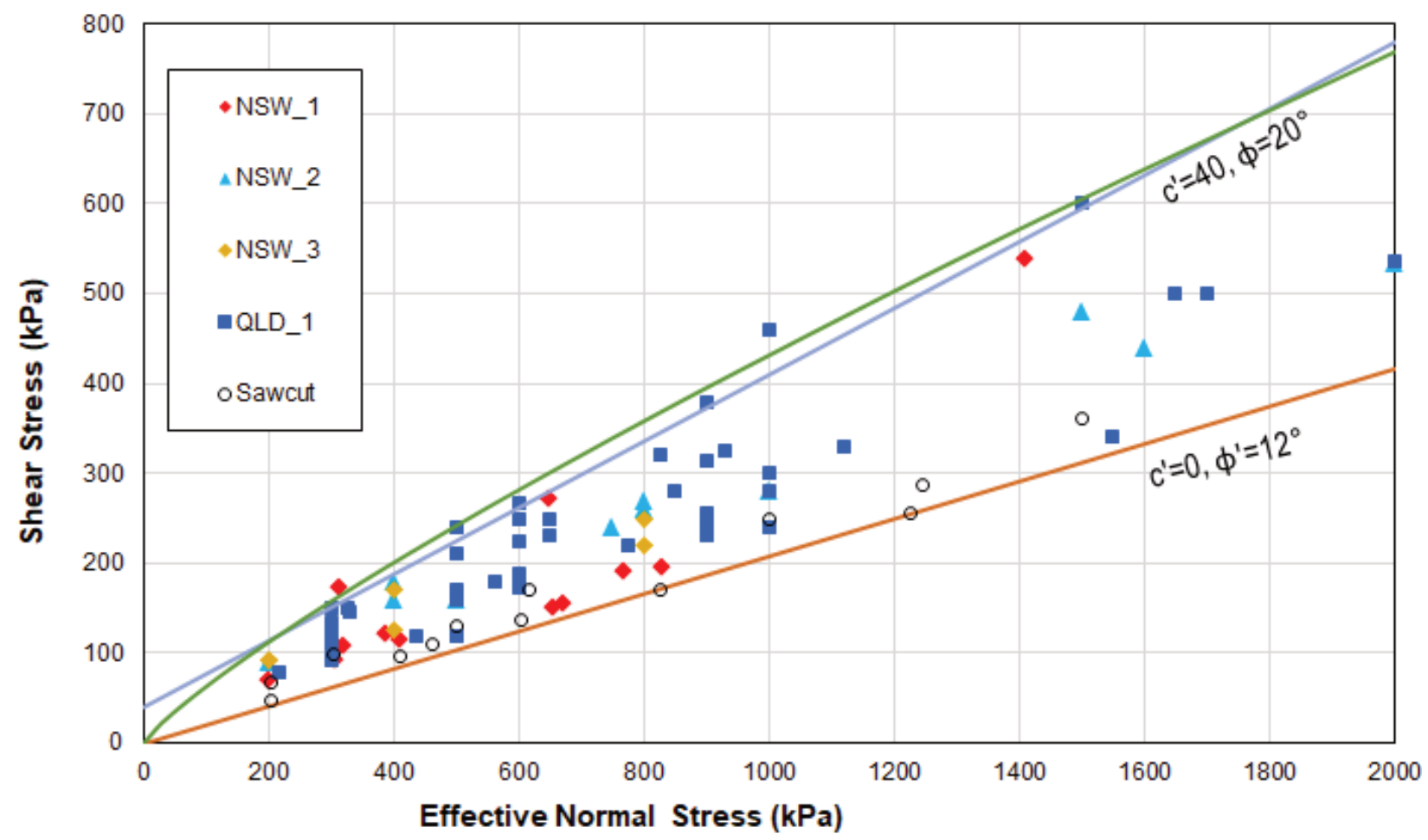

Figure 9 Residual shear strengths of tuff band defects

The tendency for tuff to crush during testing at high stress may be detrimental to the testing effort if: 1) fragments accumulate in the shear plane and act like bearings, or 2), the peripheries of the sample shear off and lead to complete crushing of the defect surface like the case in Figure 10. Methods that can be employed to minimise the potential impact of crushing on test results are:

- Utilise single stage over multi stage testing where possible.

- Minimise shear displacements during the early stage of multistage testing, although this approach requires care to ensure that the 'failure' condition is reached during earlier stages.

- Inspect (or have the lab technician inspect) the defect surface after each stage of a multistage test for signs of significant damage.

- Minimise the gap between the half boxes when cementing the test specimen into the boxes.
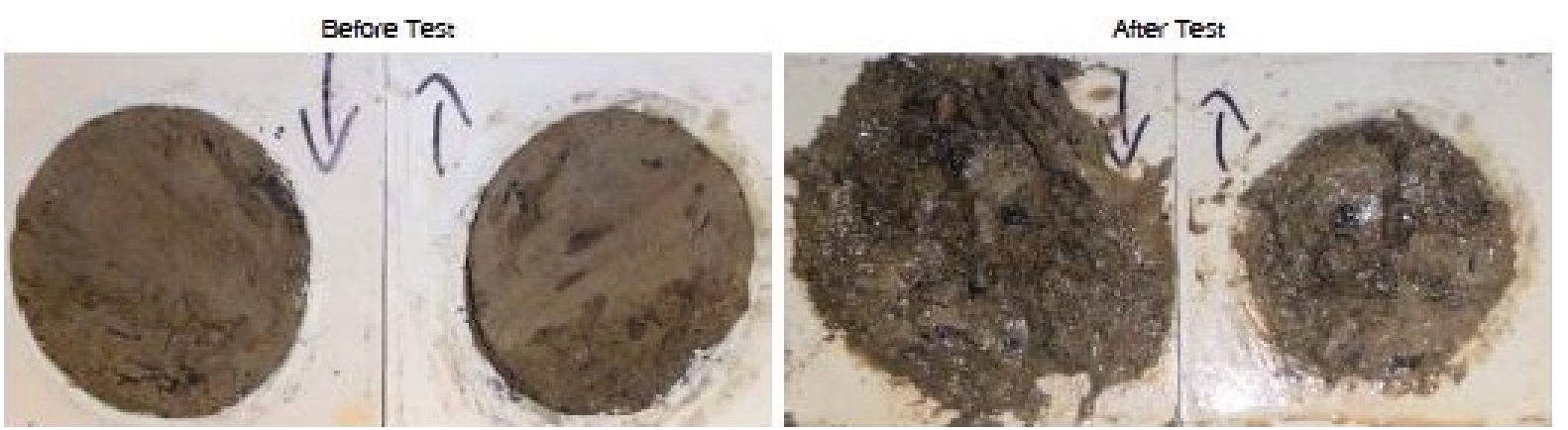

Figure 10 Example of a tuff band which has crushed during direct shear testing 
Saw cut direct shears are another method that are sometimes used by practitioners to provide an indication of a lower bound strength. Because the defect faces are effectively flat with no asperities, stresses do not concentrate at the point contacts which reduces the likelihood of crushing in the shear plane. Although there are varying opinions on the validity of saw cut tests (for example, Hencher \& Richards 2014), the saw cuts in Figure 9 compare well with the range for natural tuff defects (noting that saw cuts plot at the lower bound where a planar smooth natural defect might plot).

\subsubsection{Ring shear testing}

Ring shear testing is sometimes, but less commonly adopted than direct shear tests and provides a measure of the residual shear strength. Materials are completely remoulded and subjected to very high shear strains throughout testing, so the application of the results to tuff bands not in a residual state is probably pessimistic. Difficulties are also encountered when conducting ring shear tests at high normal stresses of about $1,000 \mathrm{kPa}$ or more, as remoulded material can extrude laterally out of the shear plane when the consolidation stress is applied. Results from ring shear testing are shown in Figure 8 to compare reasonably well with to the residual strength determined from direct shear testing.

\subsection{Back-analysis of shear strength}

Back-analysis of a slope failure is often advocated as the most reliable method for deriving shear strengths. The method is predicated on the basis that a failed slope has an average Factor of Safety (FOS) of 1 across the entire failure surface. Shear strength parameters can then be back analysed by fixing all other model variables then modifying the shear strength of interest until the reference condition is met (typically a FOS of 1). It is effectively a set of simultaneous equations with one unknown variable.

Reliability of this method diminishes when users are required to make assumptions about other model inputs with little information on which to base the assumptions. Other inputs would typically include model geometries, shear strengths for other units, and groundwater pressures. Whilst geometries may be readily available from the geological and survey models, and the strength for other units may be assessable using conventional methods, groundwater pressures are generally the greatest unknown.

Seldom is it the case that groundwater monitoring data is available with sufficient detail at the failure site to inform a pore pressure estimate. In these cases (almost always), practitioners must exercise some engineering judgement to estimate pore pressures, in which case the back analysed shear strength of a tuff band is only as reliable as the user's ability to guess the groundwater conditions. For an excavated rock slope this would require an estimate of the far-field watertable elevation, the drawdown of the watertable/s towards the pit, and the distribution of pore pressures beneath the watertable with respect to nonhydrostatic conditions and compartmentalisation. Whilst guessing a groundwater profile is seemingly simpler in a footwall or low wall scenario, the situation may be complicated by potential artesian pressures, particularly if low-permeability tuff bands impede vertical drainage. Groundwater modelling may provide useful insight, but the results will remain unsubstantiated without monitoring for calibration.

\subsection{Correlations with plasticity}

Various correlations are available which permit the user to readily infer strength characteristics from Atterberg limit testing. This is appealing in that plasticity tests are cheap and can often be conducted on samples which are not suitable for conventional shear strength testing. Notwithstanding the fact that they are a second order assessment, there are several pitfalls with using these correlations.

Firstly, the correlations provide an estimate of friction angle and not cohesion. As such, the resulting strength estimates may be unsuitable for in situ materials where significant cohesion is maintained. Secondly, the 'friction angle' can take many forms. Whilst residual friction angle is commonly the correlated parameter, many others are referenced in the literature:

- Kenney (1967) refers to residual and 'drained' friction angles. 
- Holtz \& Kovacs (1981) refer to a 'friction angle' of unknown type at the peak principal stress ratio.

- Stark \& Eid (1994) refer to residual friction angles (with caveats about ball milling samples prior to testing).

- Stark et al. (2005) refers to a fully softened friction angle.

- Casey \& Germaine (2013) refer to the critical state friction angle.

The different meanings of each friction angle are potentially significant, and the user must be cognisant of these differences. Thirdly, the values in different correlations are derived from different test types including ring shear, direct shear and triaxial shear. Lastly, chemical structure of some clays may be modified by heating of the clay when preparing testing specimens, and this in turn may modify the plasticity results.

The extreme variability in friction angle that may result from different correlations is highlighted by Figure 11. The plot on the left shows plasticity results of tuff bands from coal deposits in NSW, Qld and Colombia. A similar range is reported by Johnston et al. (2015) for tuffs in the Newcastle Coal Measures where the median plasticity index is <20. The plot on the right of Figure 11 from Suzuki et al. (2005) plots friction angle against liquid limit based on data obtained from a large number of other studies. For a liquid limit of $50 \%$ the friction angle is between 8 and $28^{\circ}$. A sensitivity analysis may indicate substantially different stability outcomes for these two values.

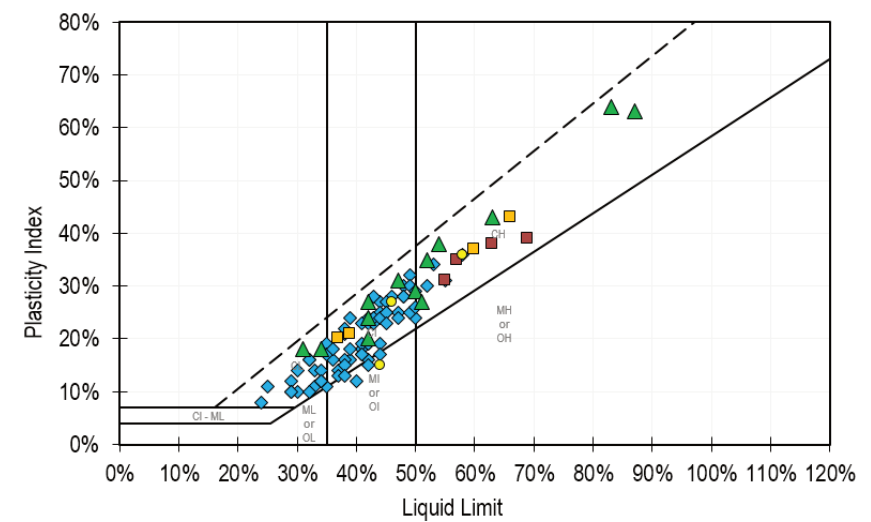

(a)

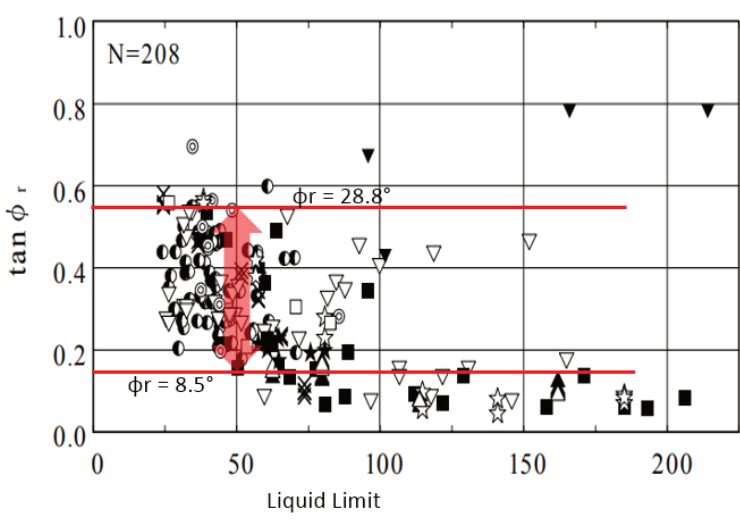

(b)

Figure 11 (a) Plasticity results for air fall tuffs from coal deposit; and (b) Large range of friction angles illustrated for a liquid limit of 50\%. Image on right modified from Suzuki et al. (2005)

\section{$6 \quad$ Failure mechanisms for slopes containing tuff bands}

\subsection{Introduction}

Some tuff bands have high intact strengths, comparable to or higher than adjacent coal seams or interburden beds. These tuff bands pose little issue for slope stability due to their high strength. In these instances, it may be appropriate to not explicitly consider the tuff bands as individual structures, but group them as part of a broader-scale rock mass domain.

Instability of coal mine slopes associated with tuff bands tends to only occur where tuff bands are sheared or have soil-like characteristics. Because they are thin and have an extremely high lateral continuity, these weak tuff units effectively represent weak geological structures which are parallel to bedding. These may lead to very large failures depending also on the slope geometries and tuff band orientations.

Various mechanisms for slope failures associated with tuff bands are discussed in the following paragraphs. 


\subsection{Highwalls and endwalls}

Because coal mines typically advance in the down dip direction, bedding dips are often relatively flat or dipping into slope at angles up to $15^{\circ}$. Steeper inward bedding dips and outward bedding dips are comparatively rare. Although flat or into-the-slope dips are a seemingly favourable condition, weak tuff bands throughout the sequence still have the potential to form an active-passive type wedge with basal sliding along the tuff bands, and in some instances may slide up dip, Figure 12. Other factors which promote this mechanism are unfavourably orientated and pervasive structures (i.e. faults or dykes) or weathered rock mass in the back scarp region.

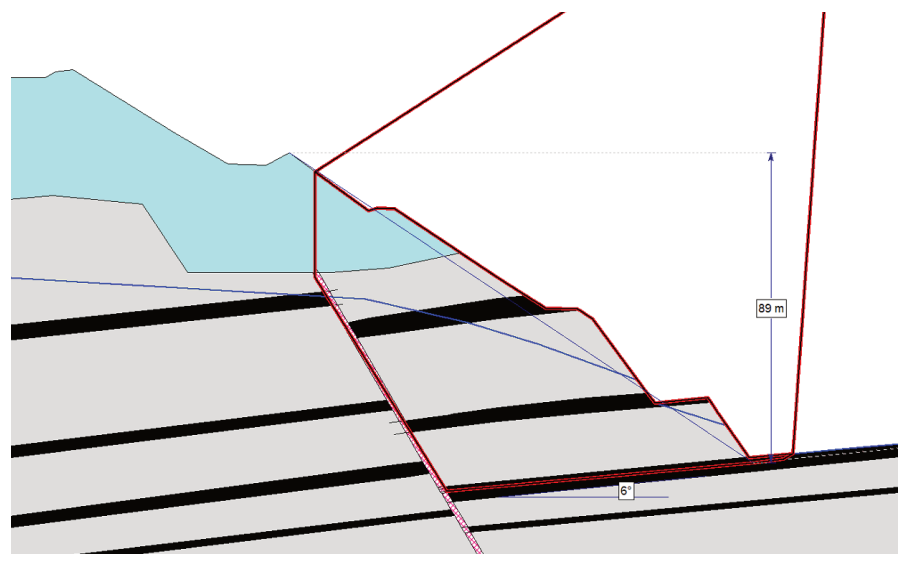

(a)

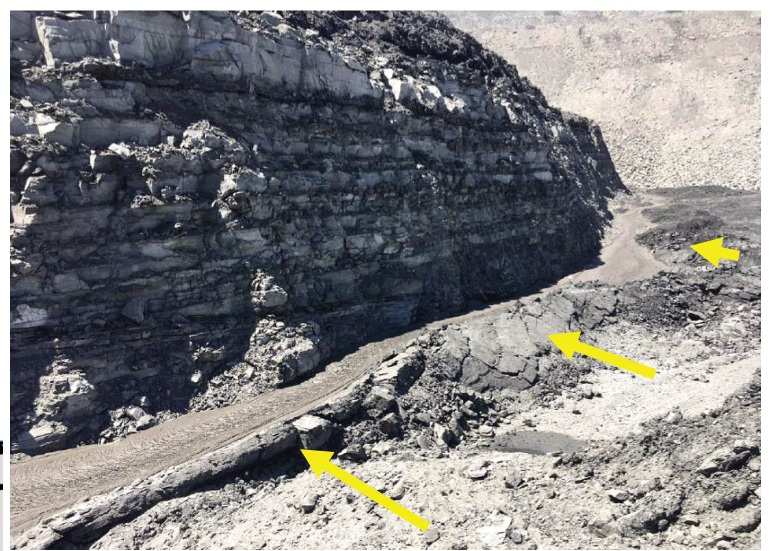

(b)

Figure 12 (a) Geometry of an endwall instability which occurred via sliding up dip along a tuff band contained within a coal seam. Coal seam dip is around $6^{\circ}$ with failure height of around $90 \mathrm{~m}$; and (b) Floor heave in the coal roof prior to coal extraction (see yellow arrows)

Highwall and endwall instability may also occur where the slope is located near the axis of a syncline with bedding dips increasing behind the slope, Figure 13. In this example the highwall design was intended to maximise extraction up to the mining lease boundary, but resulted in cracking along the crest for a strike length of $400 \mathrm{~m}$ at the locations where the coal seams sub cropped beneath a highway corridor. The slope exhibited stick-slip behaviour following large rainfall and some blasting events and was remediated by dumping a spoil buttress in front of the slope.

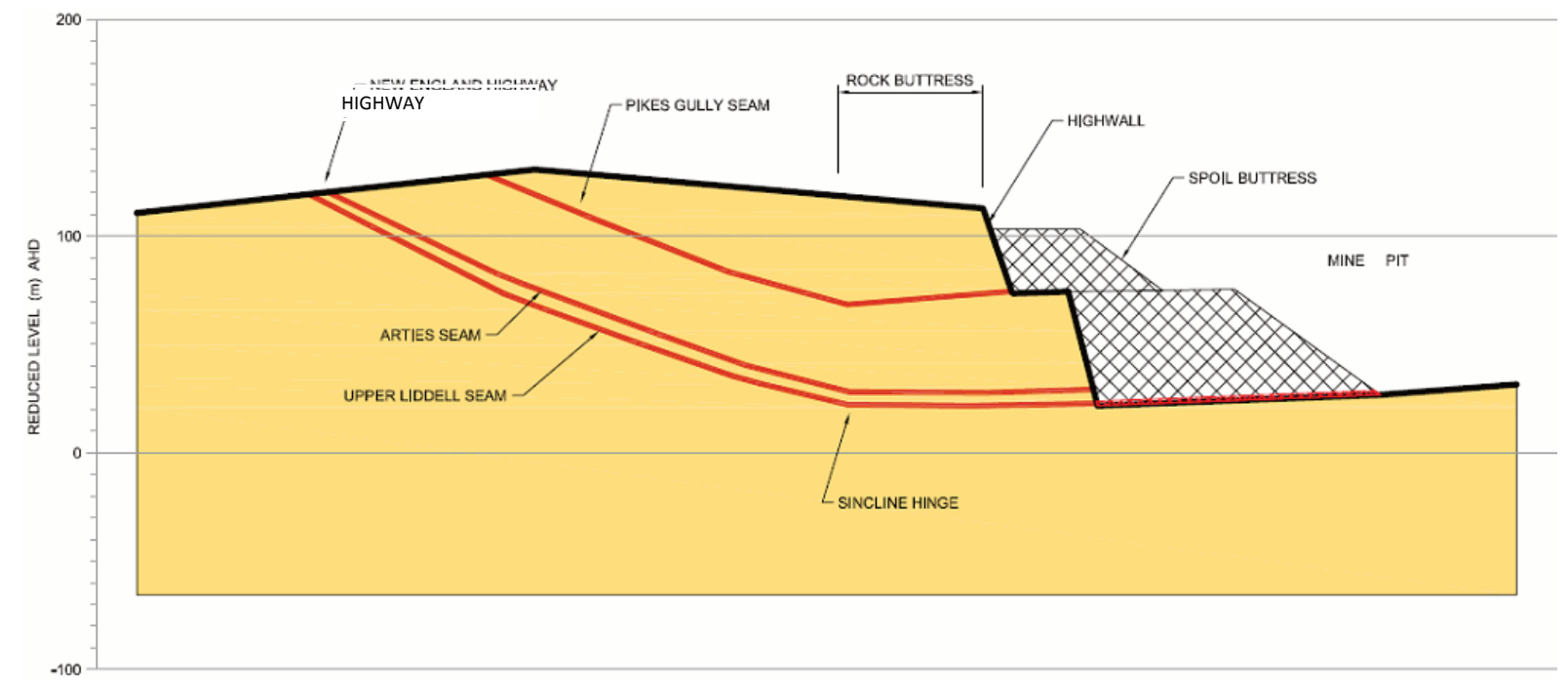

Figure 13 Example where sliding occurred along tuff bands and resulted in cracking of a highway near the sub crop of the coal seams which contained the tuff bands. Note the mining lease does not extend past of the 'rock buttress' corridor; hence a footwall approach could not be adopted 


\section{$6.3 \quad$ Footwalls}

Footwall slopes are excavated parallel to bedding and can be broadly categorised as unbenched, where a continuous slope is formed along single coal seam floor, or benched, where the slope comprises a number of footwall segments separated by berms, Figure 14. The need to implement benches is a function of the geotechnical conditions, coal seam dips and overall slope height.

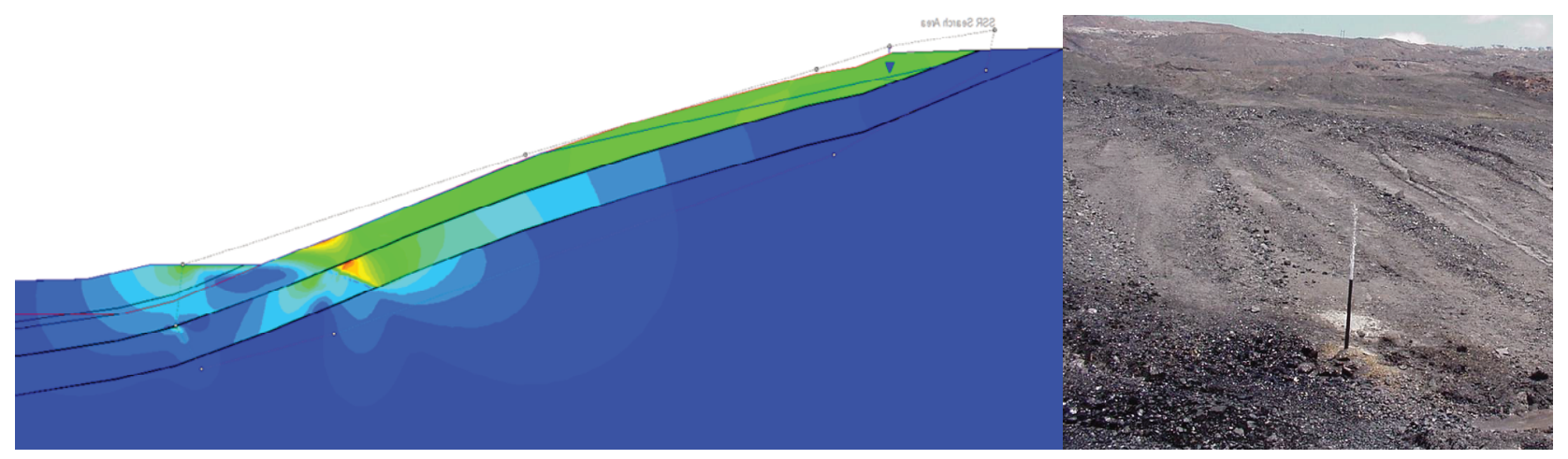

(a)

(b)

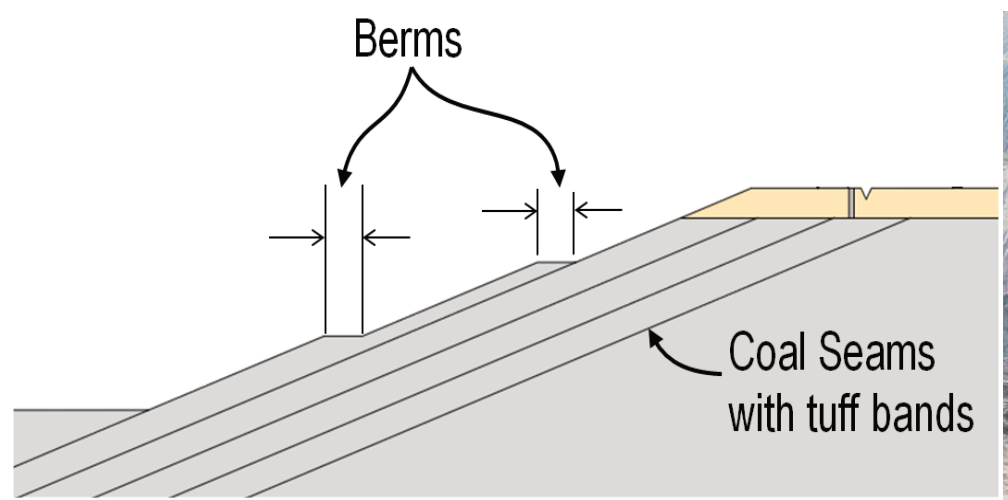

(c)

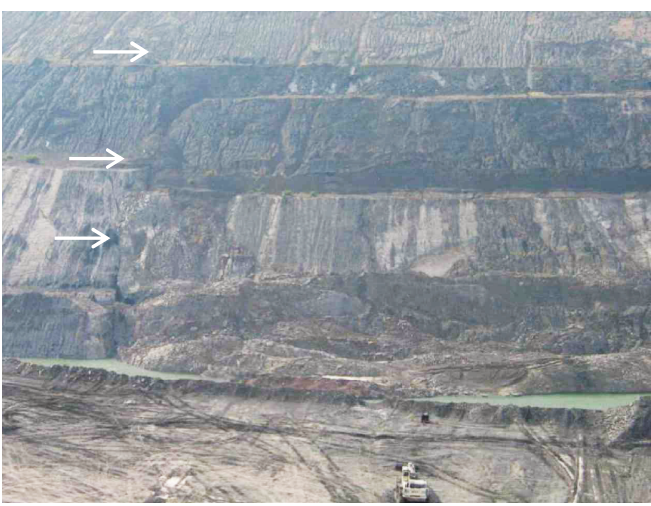

(d)

Figure 14 (a) Example of an unbenched footwall slope; (b) Artesian pressures ejecting water from a vertical well installed into the toe of an unbenched footwall slope; (c) Example of a benched footwall slope; and (d) Triple bench failure of a benched footwall slope with total height of around $120 \mathrm{~m}$. White arrows indicate head and side scarp. Note buckling in the toe region

The presence of weak and persistent defects, such as tuff bands within the footwall slope is a key hazard for footwall stability. A higher rate of bedding-parallel shearing is often observed in these steeper dipping deposits due to the increased level of folding and/or thrust faulting. Along with defect shear strength, the toe breakout strength and groundwater pressures are other key factors which govern stability. Artesian groundwater pressures are commonly observed in footwalls, particularly at the toe, as the low permeability and laterally persistent tuff units can impede vertical drainage from the slope. Whilst conventional horizontal drain holes or sub-vertical artesian relief drain holes can be drilled to assist with managing pore pressures, their effectiveness may be compromised over time due to creep movements along the basal shear plane. Poor management of surface water around the coal seam sub crops can also recharge pore pressures if water can permeate down slope along the coal seams.

Very large footwall slopes may be exposed in terrace mining operations if the pit is not backfilled when mining advances along strike (for example, to prevent resource sterilisation or for geotechnical considerations). Footwalls with very large exposure areas and containing tuffs bands then have the ability to generate very large slope failures. The largest coal mine footwall failure which is known to the author comprised an unbenched footwall with; an average dip of only $16^{\circ}$, overall height around $200 \mathrm{~m}$, failure strike length of around $2 \mathrm{~km}$ and depth to the failure plane varying between 25 and $30 \mathrm{~m}$. The total failure volume was 
estimated to be around 25 to 30 million cubic meters. In a footwall slab of this size, some degree of progressive failure (discussed earlier) can be expected due to variability of the stress, stiffness, and displacements at various points throughout the slab and along the basal shear plane. As a result, the peak strength may not be mobilised at all points at any one time.

\subsection{Spoil piles}

The economics of strip mining are maximised by placing mine spoil into the mined-out strips as close as possible to the current mining area using haul trucks or draglines. Steeper overall dump profiles reduce material handling costs but increase geotechnical risk.

Tuff materials may be present within the placed spoil material, but not in significant proportions and not forming continuous layers. They are potentially hazardous though when they remain intact in the spoil pile foundation, as the immediate coal seam floor material, or as deeper layers constrained within the floor strata. Key features relating to spoil pile foundation failures are similar to those discussed for footwall failures - requiring toe breakout and with potentially complex artesian pressures - but also requiring the back scarp to propagate through the spoil material. An active-passive or two-wedge mechanism is commonly observed and has been investigated in depth by Dunbavan (1979).

Cracking along the spoil pile crest lines is frequently observed soon after spoil placement. This is symptomatic of normal settling behaviour and does necessarily indicate impending instability. Floor heave in the toe region is often the first significant sign that foundation failures are starting to develop. In many instances the instability does not progress beyond minor heave in the order of a few metres or less and may be manageable using various operational procedures. Self-stabilisation following minor heave can be explained by progressive failure concepts; particularly if peak strength in the spoil is not mobilised before failure has induced residual strength along the basal shear plane and in the toe breakout zone where heaving occurs. In rarer cases, extremely large failures may develop and exhibit extremely large displacements. Failure volumes commonly exceed $1 \mathrm{Mbcm}$ and there are at least two instances over the last 15 years where failure volumes have been in the order of $30 \mathrm{Mbcm}$. In one of these cases the pit floor heaved, vertically, more than $50 \mathrm{~m}$ into the air and pushed the low wall across to the highwall. It was later determined that sliding occurred along a tuff band at a depth of around $10 \mathrm{~m}$ in the foundation where artesian pressures were also measured.

The risks associated with foundation failures can be mitigated by excavating the weak floor material or blasting the floor to disrupt potentially weak shear planes such as tuff bands before spoil is placed. The costs to implement these measures may be significant, but justified if they can prevent spoil pile failure. Relief of artesian pressure is also of benefit for stability where artesian conditions exist.

\subsection{Dragline bench}

Draglines are commonly used in flatly-bedded coal deposits to remove waste rock and uncover coal seams that are later extracted using truck-shovel fleets. Draglines work by sitting on the spoil pile and side casting spoil into the previous strip as it advances along the strike. Depending on the dig sequence, this may require the dragline to operate on a dragline bench overlying a coal seam, Figure 15. 


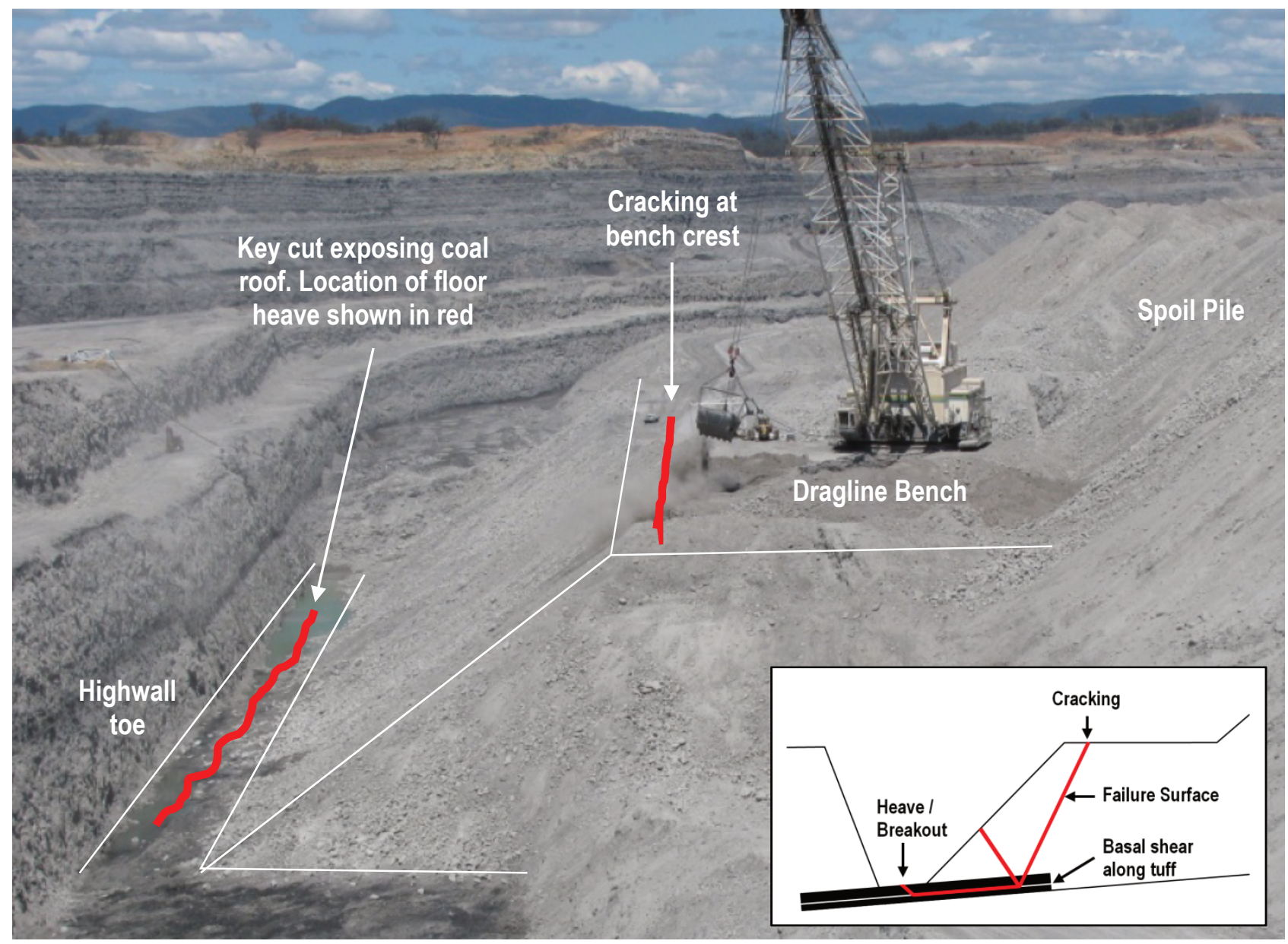

Figure 15 Example of dragline bench where minor heave was observed in the coal roof during the key cut. The inset shows the inferred mechanism with sliding along a tuff band within the coal seam. For scale, the dragline bench level is approximately $50 \mathrm{~m}$ above the coal roof level

Dragline bench instability may occur during the 'key cut' if the coal seams underlying the working bench contain weak tuff bands or other weak features. Whilst complete failure is relatively uncommon, the instabilities often manifest as heaving in the coal roof and cracking/slumping on the dragline bench. Commonly observed self-stabilising effects may again be attributable to progressive failure concepts and the stress-strain compatibility throughout the slope, and contrasting shear stiffness of tuff bands and spoil. Allowing water to pond in the key cut is also a known risk factor and may contribute to softening of the tuff bands depending on the rates of water of ingress. The risk can be managed by modifying the dig sequence to leave some material in key cut for later extraction or positioning the dragline further back on the bench or further along strike (which may reduce productivity).

\section{$7 \quad$ Conclusions}

Ash fall tuff bands of volcanic origin are common geological features in coal deposits throughout Australia and elsewhere throughout the world. They are typically clay-rich due to post-depositional alteration and with varying degrees of cementation depending on the depositional environment and alteration processes. Geological and mining-induced processes such as tectonic deformation, swelling, progressive failure and creep deformation can also significantly modify the in situ characteristics of tuff bands.

When tuff bands are intact with high degrees of cementation, they pose little problem for the stability of coal mine slopes. Softening or shearing due the processes discussed above may reduce the strengths in which instance tuff bands may become hazardous for slope stability. A number of instability mechanisms have been discussed, as have other key factors which influence stability and slope management practices. Because 
processes like softening, progressive failure and creep deformations are time-dependant, slopes may remain stable following mining but develop instability after sufficient time is provided for a change in conditions to occur.

Characterising the shear strength of sheared or weak intact tuff bands can be difficult for several reasons. Back-analysis of prior instabilities may provide a direct indication of the mobilised strengths at failure, but, requires knowledge or estimates of the other model components. Seldom is the case that groundwater monitoring exists at the instability locations, in which case back analysed strengths are limited by the reliability of the estimated pore pressure profiles (and other adopted model parameters such rock mass strengths, model geometries etc.). Alternatively, laboratory testing can be used to estimate strengths, but may be limited by the ability to obtain samples that are adequate for testing and which are representative of the anticipated conditions at the time of potential slope failure. It is generally the weak intact or sheared tuff units which are critical for slope stability, yet these units are often damaged as part of the drilling, handling and testing process, or their properties may be sensitive to changes in moisture content and swelling at low confinement. Furthermore, the in situ conditions may change after drilling and sampling due to several of the processes which have been discussed above.

In order to provide reliable stability estimates for slopes containing tuff bands it is fundamentally important that the range of potential tuff band shear strengths be considered, and that the adopted shear strength matches the anticipated in situ conditions. Whilst there may be the temptation to default to a residual shear strength value, this can provide pessimistic outcomes if there is no precedent or geological evidence to suggest that such conditions may develop. On the contrary, optimistic stability estimates may result if intact or peak strength values are used but if softened or residual conditions exist or develop. Strength estimates would ideally use a combination of geological observations, precedent experience, back-analysis, and laboratory testing as no single method provides a definitive strength estimate. Slope deformation monitoring may also be useful to identify factors such as creep and strain softening.

\section{Acknowledgement}

The author acknowledges that some of the photographs in Section 6 have been adopted from internal company reports. The sources have not been referenced for confidentiality purposes.

\section{References}

Bayly, KW 2012, 'Not what it seams', Proceedings of the 38th Symposium on the Geology of the Sydney Basin-Advances in the study of the Sydney Basin, Coalfield Geology Council of NSW, Maitland.

Beckett, J 1988, Notes to Accompany the 1:100,000 Hunter Coalfield Geological Map, Coal Geology Branch, NSW Department of Mineral Resources.

Bjerrum, L 1967, 'The third Terzaghi Lecture; progressive failure in slopes of overconsolidated plastic clay and clay shales', Journal of the Soil Mechanics and Foundations Division, vol. 93, iss. 5, pp. 1-49.

Bohor, BF \& Triplehorn, DM 1993, Tonsteins: Altered Volcanic-Ash Layers in Coal-Bearing Sequences, The Geological Society of America Special Publication 285.

Casey, B \& Germaine, JT 2013, 'Stress dependence of shear strength in fine grained soils and correlations with liquid limit', Journal of Geotechnical and Geoenvironmental Engineering, vol. 137, no. 10, pp. 1709-1717.

Chowdhury, R, Flentje, P \& Bhattacharya, G 2010, Geotechnical Slope Analysis, Taylor \& Francis Group, Boca Raton.

Dai, S, Ward, CR, Graham, IT, French, D, Hower, JC, Zhao, L \& Wang, X 2017, 'Altered volcanic ashes in coal and coal-bearing sequences: a review of their nature and significance', Earth Science Reviews, vol. 174, pp. 44-74.

Diessel, CFK 1985, 'Tuffs and tonsteins in coal measures of New South Wales, Australia', Proceedings of the 10th International Congress on Carboniferous Stratigraphy and Geology, Elsevier, Paris.

Diessel, K 1992, Coal Bearing Depositional Systems, Springer-Verlag Publishing, Berlin.

Dunbavan, M 1979, Sequential Failure of Granular Slopes, PhD thesis, James Cook University, Townsville.

Duncan, JM, Wright, SG \& Brandon, TL 2005, Soil Strength and Slope Stability, John Wiley \& Sons Publishing, New Jersey.

Galvin, J 2016, Ground Engineering - Principles and Practices for Underground Coal Mining, Springer International Publishing, Switzerland.

Grevenitz, P, Carr, P \& Hutton, A 2003, 'Origin, alteration and geochemical correlation of Late Permian airfall tuffs in coal measures, Sydney Basin, Australia', International Journal of Coal Geology, vol. 55, pp. 27-46. 
Gulson, BL, Diessel, CFK, Mason, DR \& Krogh, TE 1990, 'High precision radiometric ages from the northern Sydney Basin and their implications for the Permian time interval and sedimentation times', Australian Journal of Earth Sciences, vol. 37, pp. 459-469.

Hencher, S \& Richards, LR 2014, 'Assessing the shear strength or rock discontinuities at laboratory and field scale', Rock Mechanics and Rock Engineering, vol. 48, no. 3, pp. 883-905.

Holtz, RD \& Kovacs, WD 1981, An Introduction to Geotechnical Engineering, Prentice-Hall Publishing, New Jersey.

Huff, W 2016, 'K Bentonites; a review', American Mineralogist, vol. 101, pp. 43-70.

Hutton, AC 2009, 'Geological setting of Australasian coal deposits', in R Kininmonth \& E Baafi (eds), Australasian Coal Mining Practice, The Australasian Institute of Mining and Metallurgy, Carlton, pp. 40-84.

Johnston, J, Fityus, S, Buzzi, O, Rodgers, C \& Kingsland, R 2015, 'Engineering properties of Permian clay tuffs', Engineering Geology for Society and Territory, vol. 6, pp. 273-278.

Kenney, TC 1967, 'The influence of mineral composition on the residual strength of natural soils', Proceedings of the Geotechnical Conference on Shear Strength Properties of Natural Soils and Rocks, Norwegian Geotechnical Institute, Oslo, pp. 123-129.

Kramer, W, Weatherall, G \& Offler, R 2001, 'Origin and correlation of tuffs in the Permian Newcastle and Wollombi Coal Measures, NSW, Australia, using chemical fingerprinting', International Journal of Coal Geology, vol. 47, pp. 115-135.

Martin, D \& Stacey, P 2018, Guidelines for Open Pit Slope Design in Weak Rocks, CSIRO Publishing, Clayton.

Sainsbury, B 2003, An Investigation of the Pillar System Stability Over Softened Claystone Floors at the Cooranbong Colliery, MSc thesis, UNSW Sydney, Sydney.

Schultz, LG 1962, 'Nonmontmorillonitic composition of some bentonite beds', Clays and Clay Minerals, vol. 11, no. 1, pp. 169-177.

Seedsman, RW \& Mallett, CW 1988, Claystones of the Newcastle Coal Measures, End of Grant Report Number 749, National Energy Research, Development and Demonstration Program, Department of Primary Industries and Energy, Commonwealth of Australia, Canberra.

Skempton, AW 1970, 'First-time slides in over-consolidated clays', Geotechnique, vol. 20, no. 3, pp. 320-324

Stark, TD \& Eid, HT 1994, 'Drained residual strength of cohesive soils', Journal of Geotechnical Engineering Division, vol. 120, no. 5, pp. 856-871.

Stark, TD, Choi, H \& McCone, S 2005, 'Drained shear strength parameters for analysis of landslides', Journal of Geotechnical and Geoenvironmental Engineering, vol. 131, no. 5, pp. 575-588.

Suzuki, M, Tsuzuki, S \& Yamamoto, T 2005, 'Physical and chemical index properties of residual strength of various soils' viewed on 14 October 2019, https://www.researchgate.net/publication/30793105_Physical_and_chemical_index_properties_of_ residual_strength_of_various_soils

Taylor, RK \& Smith, TJ 1986 'The engineering geology of clay minerals: swelling, shrinking and mudrock breakdown', Clay Minerals, vol. 22, pp. 235-260.

Zhao, L 2012, Mineralogy and Geochemistry of Permian Coal Seams of the Sydney Basin Australia, and the Songzao Coalfield, SW China, PhD thesis, UNSW Sydney, Sydney. 
